\title{
Yvette Selim
}

University of Technology Sydney,

Australia

Email: yvette.selim@uts.edu.au

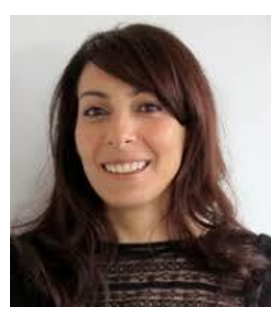

\section{Gareth Wall}

University of Birmingham

United Kingdom

Email:wallgareth@gmail.com

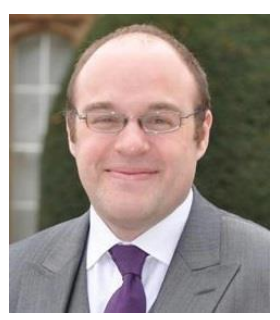

\section{Editorial}

Participation in the decisions that affect our lives is the basic premise for democratic engagement. Greater participation can lead to more inclusive development and better scrutiny of public officials, ensuring greater efficiencies, reduced corruption and equitable access to services. It is only through the inclusive participation of women, minorities, people with disabilities and migrants in issues of local governance that the global commitment to 'leave no one behind' entrenched in the UN's Sustainable Development Goals (SDGs) may be realised. It is within the frame of inclusive, sustainable, accountable, transparent and equitable local government committed to in the Commonwealth Principles that papers published in this issue should be viewed. The issue provides a critical perspective on recent developments from across the Commonwealth and beyond, which contributes to our growing evidence base of good practice.

Our first paper by Yves Cabannes maps both the Commonwealth experience and global good practice in participatory budgeting, while advocating for its potential role in achieving the commitment to participatory governance within the SDGs. Drawing on three decades of innovations, with substantial inter- and intra-country learning, the paper provides an invaluable catalogue of examples for practitioners from villages to towns, and from cities and metropolises to states. This is complemented by Helen Christensen's paper which maps the development of reporting requirements for community engagement in Australia's local government systems. She shows how local authorities use four 
different types of approaches, often simultaneously: 'prescriptive', 'aspirational', 'empowering' and 'hedging'. Christensen argues that while community engagement now occupies a central place in local governance in Australia it faces a number of key issues and challenges.

David Anaafo then takes us to Ghana where he uses a heuristic continuum to undertake a statute-based politico-administrative review of the local governance system to ascertain the extent of decentralisation. He concludes that the legislative, political and administrative arrangements in place make it easy for the centre to usurp the powers of local authorities. Following this, in his paper on municipal finance for housing, Christopher Feather argues that when local governments engage in housing with innovation and financial pragmatism, the housing needs of the urban poor and vulnerable can be better served. Heading back to the Pacific, Joany Grima examines the role local government plays in enabling community events in New Zealand. Through a comparative case study analysis of two neighbouring communities, she finds that while social and economic impacts on the local community were generally positive in nature, there is scope for greater strategic planning around community event delivery, both by individual authorities and collaboratively. Drawing on extensive fieldwork in Nepal, Keshav Acharya and Habib Zafarullah analyse factors influencing effective service delivery at the grassroots level. Their findings indicate that a wide range of governance arrangements have been deployed in an effort to achieve effective service delivery and that many community-based organisations lack a solid governance system for their development undertakings, leading to poor performance and a lack of accountability.

To close the issue, we stay in South Asia with a detailed commentary from Noor Akbar, Commonwealth Local Government Forum (CLGF) programme officer, on how CLGF's EU-funded programme is seeking to strengthen the associations of local governments to enhance governance and effective development outcomes in Pakistan. This is followed by a review by Soumyabrato Bagchi of Tofail Ahmed's recent book Bangladesh: Reform Agenda for Local Governance. 